\title{
Levantamento florístico e fitossociológico de praças públicas do município de Dom Pedro/MA
}

As áreas verdes urbanas constituem-se em espaços de grande relevância para a melhoria da qualidade ambiental das cidades, sendo objeto de diversos estudos no meio acadêmico. Objetivou-se nesta pesquisa, avaliar a composição florística e a estrutura fitossociológica da arborização de quatro praças públicas urbanas do município de Dom Pedro/MA: José Tonico; Magalhães de Almeida; Teixeira de Freitas; Matriz. Para tal, realizou-se um inventário total da composição florística das praças, através de análise visual, além da caracterização fitossociológica por meio da análise dos seguintes parâmetros ecológicos: riqueza, índice de ShannonWeaver $\left(\mathrm{H}^{\prime}\right)$, equabilidade de Pielou $\left(\mathrm{J}^{\prime}\right)$, índice de dominância de Simpson e índice de similaridade de Jaccard. Os resultados mostraram que foram identificados 67 indivíduos, distribuídos em 12 espécies e 8 famílias botânicas. Arecaceae e Fabaceae foram as famílias de maior ocorrência e Ficus benjamina L. a espécie com maior número de indivíduos (35), equivalente a 52,24\% do total registrado. Quanto à origem, 91,7\% das espécies utilizadas na arborização das praças são exóticas com apenas 8,3\% nativas do território brasileiro. As praças Magalhães de Almeida, Teixeira de Freitas e Matriz foram classificadas como de baixa diversidade de espécies $\left(H^{\prime}<1,5\right)$. Em termos de similaridade, as praças Magalhães de Almeida e Teixeira de Freitas apresentaram maior semelhança em sua composição florística.

Palavras-chave: Arborização; Áreas verdes; Diversidade de espécies.

\section{Floristic and phytosociological survey of public squares in the municipality of Dom Pedro/MA}

\begin{abstract}
Urban green areas are spaces of great importance for improving the environmental quality of cities, being the subject of several studies in the academic environment. The objective of this research was to evaluate the floristic composition and the phytosociological structure of the afforestation of four urban public squares in the city of Dom Pedro/MA: José Tonico; Magalhães de Almeida; Teixeira de Freitas e Matriz. To this end, a total inventory of the floristic composition of the squares was carried out, through visual analysis, in addition to the phytosociological characterization through the analysis of the following ecological parameters: richness, Shannon-Weaver index $\left(\mathrm{H}^{\prime}\right)$, Pielou's equability $\left(\mathrm{J}^{\prime}\right)$, Simpson's dominance index and Jaccard similarity index. The results showed that 67 individuals were identified, distributed in 12 species and 8 botanical families. Arecaceae and Fabaceae were the families with the highest occurrence and Ficus benjamina L. the species with the largest number of individuals (35), equivalent to $52.24 \%$ of the total registered. As for the origin, $91.7 \%$ of the species used in the afforestation of the squares are exotic, with only $8.3 \%$ native to the Brazilian territory. The Magalhães de Almeida, Teixeira de Freitas and Matriz squares were classified as having low species diversity $\left(\mathrm{H}^{\prime}<1.5\right)$. In terms of similarity, the squares Magalhães de Almeida and Teixeira de Freitas showed greater similarity in their floristic composition.
\end{abstract}

Keywords: Afforestation; Green areas; Species diversity.

Topic: Planejamento Urbano

Reviewed anonymously in the process of blind peer
Received: 06/10/2020

Approved: $\mathbf{2 8 / 1 1 / 2 0 2 0}$
Adeval Alexandre Cavalcante Neto ic Instituto Federal do Maranhão, Brasil http://lattes.cnpq.br/7574248016262916 http://orcid.org/0000-0003-4102-8491 adeval@ifma.edu.br

Gabriel Claudino Sales dos Santos (iD Instituto Federal do Maranhão, Brasil http://lattes.cnpq.br/2282347253147462 http://orcid.org/0000-0001-6577-2616 salesclaudino05@gmail.com

Teresa Cristina Ferreira da Silva Gondim (D) Instituto Federal do Maranhão, Brasil http://lattes.cnpq.br/4092432225146062 http://orcid.org/0000-0002-9488-4163 teresa.silva@ifma.edu.br

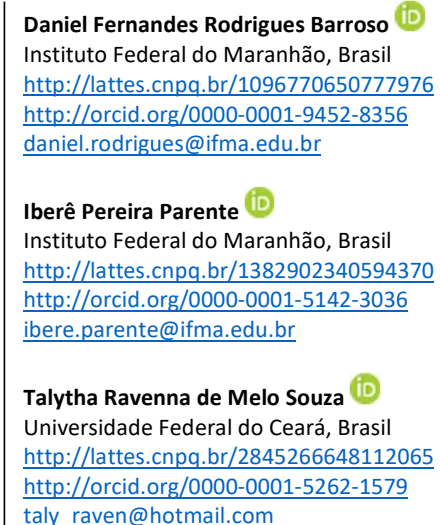

Valéria Melo Costa (id

Universidade Estadual do Maranhão, Brasil http://lattes.cnpq.br/2096699379083656 http://orcid.org/0000-0001-6563-1370 lerinhamelo@hotmail.com
Referencing this:

CAVALCANTE NETO, A. A.; SANTOS, G. C. S.; GONDIM, T. C. F. S.; BARROSO, D. F. R.; PARENTE, I. P.; SOUZA, T. R. M.; COSTA, V. M. Levantamento florístico e fitossociológico de praças públicas do município de Dom Pedro/MA. Revista Ibero Americana de Ciências Ambientais, v.11, n.6, p.738-746, 2020. DOI: http://doi.org/10.6008/CBPC2179-6858.2020.006.0059 


\section{INTRODUÇÃO}

As áreas verdes urbanas constituem-se em espaços de grande relevância para a melhoria da qualidade ambiental das cidades, pois apresentam função paisagística, contribuem para a redução da poluição sonora, fornecem sombra para a população e são locais propícios para as práticas do desporto e lazer.

As praças são espaços públicos que geralmente apresentam grandes áreas verdes e livres de impermeabilização, que os torna área de exceção, na maioria das zonas urbanas (BRITO et al., 2012). Estas, têm uma missão de suma importância na vida dos moradores das cidades, pois são locais que propiciam o convívio social e o conforto dos indivíduos (SANTOS et al., 2013).

A arborização urbana é vista por especialistas, como um dos componentes bióticos mais importantes das cidades. Quando há planejamento, proporciona inúmeros benefícios devido suas funções ecológicas, estéticas e sociais. Por outro lado, a falta deste pode acarretar diversos transtornos, seja para a população ou para a gestão municipal (SOARES et al., 2019; MOREIRA et al., 2019).

A arborização das cidades tem despertado interesse de diversos segmentos, principalmente com a constante migração de populações rurais para as cidades, que tem contribuído para um crescimento desordenado destas e influenciado no bem-estar da população. Assim, a vegetação existente em praças urbanas é uma temática que tem ganhado destaque nas discussões que envolvem as cidades pela busca de melhor qualidade de vida para os seus habitantes (SILVA et al., 2017; DANTAS et al., 2016).

Para Gatti (2013) a leitura dos espaços públicos de uma cidade poderá fornecer indicativos para a criação de novos locais ou a até mesmo da necessidade de adaptações destes espaços, e ainda evidenciar possíveis potencialidades e conflitos de cada lugar. Nesse contexto, a realização de inventários florísticos e fitossociológicos da arborização se torna essencial para identificar a composição da flora e a estrutura desses espaços, bem como conhecer a diversidade dos componentes arbóreos existentes nas praças (SILVA et al., 2016).

Levando-se em consideração a importância da arborização em espaços públicos urbanos, esta pesquisa teve como objetivo avaliar a composição florística e a estrutura fitossociológica da arborização nas principais praças do município de Dom Pedro-MA.

\section{MATERIAIS E MÉTODOS}

A pesquisa foi desenvolvida no município de Dom Pedro, situado na mesorregião central do estado do Maranhão, Nordeste Brasileiro, compreendendo uma área de 358,493 km² e uma população estimada de 23.350 habitantes (IBGE, 2019).

Segundo a classificação de Köppen, o clima da cidade é tropical ( $\left(\mathrm{WW}^{\prime}\right)$ subúmido seco, apresentando precipitação média anual em torno de $1.317 \mathrm{~mm}$ e com períodos bem definidos: um chuvoso, que se estende de dezembro a maio, e outro seco, que vai de junho a novembro. A vegetação é composta pela Floresta Decidual Estacional. O solo predominante é Podzólico Vermelho-Amarelo (CORREIA FILHO et al., 2011). 
O estudo foi realizado entre os meses de outubro/2019 a março/2020 em quatro praças: A. José Tonico; B. Magalhães de Almeida; C. Teixeira de Freitas; D. Matriz (Figura 1), que foram selecionadas por representarem as principais e mais frequentadas áreas públicas do município.
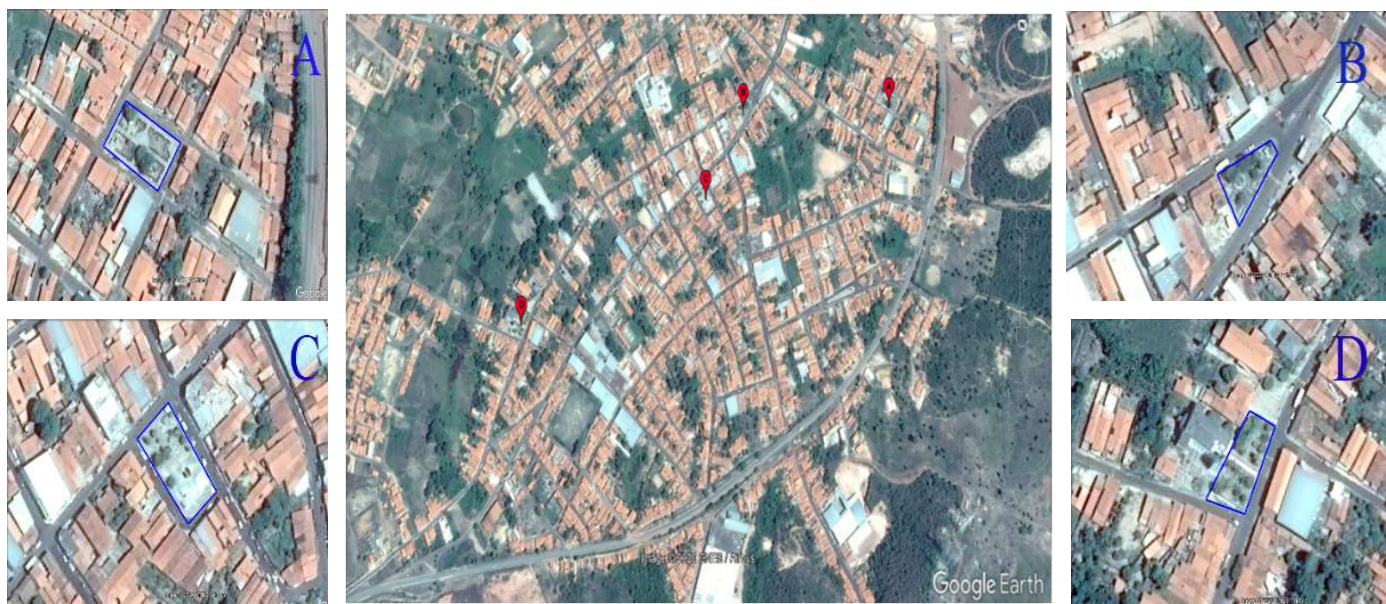

Figura 1: Localização das praças estudadas na cidade de Dom Pedro-MA, (A. José Tonico; B. Magalhães de Almeida; C. Teixeira de Freitas; D. Matriz). Fonte: Google Earth, 2020.

O levantamento florístico foi realizado por meio de censo, também denominado inventário total. As espécies foram identificadas através de análise visual, por meio da anotação do nome vulgar ou científico, obtido com auxílio de especialista na área e/ou bibliografia especializada. Também, fez-se registro fotográfico e coleta de material botânico, quando necessário. Para a correta classificação botânica, adotouse o sistema APG III (2009). Quanto à origem fitogeográfica, foi considerada nativa a espécie originária de formações vegetais presentes no país e, como exóticas, aquelas com ocorrência em outros ecossistemas diferentes dos que aparecem no território brasileiro (BAUMANN et al., 2019).

Para avaliar a diversidade e à similaridade das espécies foram calculados os seguintes parâmetros fitossociológicos: riqueza, índice de Shannon-Weaver $\left(\mathrm{H}^{\prime}\right)$, equabilidade de Pielou $\left(\mathrm{J}^{\prime}\right)$, índice de dominância de Simpson e índice de similaridade de Jaccard (Tabela 1).

Tabela 1: Parâmetros fitossociológicos utilizados para a avaliação da composição florística das espécies presentes nas praças públicas do município de Dom Pedro-MA.

\begin{tabular}{lll}
\hline Parâmetros & Fórmula & Referência \\
\hline Riqueza & $\mathrm{R}=\mathrm{S}$ & Melo (2008) \\
Índice de diversidade de Shannon-Weaver & \multicolumn{1}{c}{$H^{\prime}=-\sum p i(\ln p i)$} & Bernardes et al. (2019) \\
Equabilidade de Pielou & $\mathrm{J}^{\prime}=\mathrm{H}^{\prime} / \mathrm{H}_{\max }$ & Scolforo et al. (2008) \\
Índice de dominância de Simpson & $\lambda=\Sigma p i^{2}$ & Vieira et al. (2020) \\
Índice de Jaccard & $\mathrm{J}=\mathrm{c} /(\mathrm{a}+\mathrm{b}-\mathrm{c})$ & Scolforo et al. (2008) \\
\hline
\end{tabular}

Os dados foram compilados e processados em planilhas eletrônicas pelo software Microsoft Excel. 0 dendrograma de similaridade entre as espécies das praças foi desenvolvido a partir do software Past (HAMMER et al., 2011).

\section{RESULTADOS E DISCUSSÃO}

\section{Análise Florística}

No censo realizado em quatro praças públicas do município de Dom Pedro-MA, foram mensurados e 
identificados 67 indivíduos, distribuídos em 12 espécies e 8 famílias botânicas (Tabela 2).

Tabela 2: Relação das famílias e espécies vegetais, nomes populares, origens, número de indivíduos e frequência relativa registrados nas quatro praças estudadas.

\begin{tabular}{|c|c|c|c|c|}
\hline Família / Espécie & Nome Vulgar & Origem & $\mathrm{Ni}$ & Freq. \% \\
\hline \multicolumn{5}{|l|}{ Annonaceae } \\
\hline Annona squamosa $\mathrm{L}$. & Ata & Exótica & 1 & 1,49 \\
\hline \multicolumn{5}{|l|}{ Arecaceae } \\
\hline Copernicia prunifera & Carnaubeira & Nativa & 1 & 1,49 \\
\hline Dypsis lutescens & Areca-bambu & Exótica & 1 & 1,49 \\
\hline Phoenix canariensis Hort. & Palmeira-das-Canárias & Exótica & 3 & 4,48 \\
\hline Roystonea oleraceae & Palmeira Imperial & Exótica & 6 & 8,96 \\
\hline \multicolumn{5}{|l|}{ Combretaceae } \\
\hline Terminalia catappa $L$ & Amendoeira & Exótica & 1 & 1,49 \\
\hline \multicolumn{5}{|l|}{ Fabaceae } \\
\hline Senna siamea & Cássia-de-Sião & Exótica & 8 & 11,94 \\
\hline Tamarindus indica $\mathrm{L}$. & Tamarindeiro & Exótica & 1 & 1,49 \\
\hline \multicolumn{5}{|l|}{ Meliaceae } \\
\hline Azadirachta indica A. Juss & $\mathrm{Nim}$ & Exótica & 7 & 10,45 \\
\hline \multicolumn{5}{|l|}{ Moraceae } \\
\hline Ficus benjamina $\mathrm{L}$. & Ficus & Exótica & 35 & 52,24 \\
\hline \multicolumn{5}{|l|}{ Myrtaceae } \\
\hline Syzygium jambolanum & Azeitona preta & Exótica & 2 & 2,99 \\
\hline \multicolumn{5}{|l|}{ Poaceae } \\
\hline Bambusa vulgaris & Bambu & Exótica & 1 & 1,49 \\
\hline TOTAL & & & 67 & $100 \%$ \\
\hline
\end{tabular}

Nota: $\mathrm{Ni}$ = número de indivíduos; Freq. = frequência relativa.

As famílias que apresentaram maior riqueza de espécies foram Arecaceae (4) e Fabaceae (2), juntas representaram $50 \%$ do número total registrado. As demais famílias contribuíram para a composição da diversidade florísticas das praças com apenas uma espécie cada.

Arecaceae e Fabaceae também foram as famílias de maior representatividade nos inventários das praças públicas realizados por Lima et al. (2015) em Nova Xavantina - MT, Freitas et al. (2015) no Rio de janeiro- RJ, Dantas et al. (2016) em Macapá-AP e Silva et al. (2018) em Picos-PI. A família Arecaceae é um táxon muito empregado nas composições paisagísticas urbanas, devido à beleza de suas plantas, com grande potencial ornamental (MORAES et al., 2015). A família Fabaceae possui a maior diversidade florística do Brasil, apresentando notoriedade na região Nordeste, sendo muito utilizada na arborização urbana em todo o país (AMORIM et al., 2016; LINDENMAIER et al., 2008).

Nenhuma das espécies foi encontrada em todas as praças estudadas, sendo que Ficus benjamina L. e Azadirachta indica A. Juss estiveram presentes em mais locais diferentes, tendo sido identificadas em três praças.

Com relação à quantidade de indivíduos por espécie, constatou-se que as mais abundantes foram: Ficus benjamina L (35), Senna siamea (8), Azadirachta indica A. Juss (7) e Roystonea oleraceae (6), representando 83,58 \% da comunidade estudada. Destaca-se a maior contribuição de Ficus benjamina L. com 52,24\% do número total de indivíduos. Por outro lado, Annona squamosa L, Dypsis lutescens, Tamarindus indica L., Terminalia catappa L., Copernicia prunifera e Bambusa vulgaris, são as menos cultivadas nesses espaços públicos, com a presença de apenas um indivíduo.

Para que ocorra uma boa diversidade no meio urbano, recomenda-se que as espécies de uma área não ultrapassem os valores de $10 \%$ de uma mesma espécie e $30 \%$ de uma única família (CEMIG, 2011). 
Percentuais superiores podem ocasionar transtornos consideráveis, caso haja ataques de determinadas pragas ou doenças (SANTAMOUR JÚNIOR et al., 2002). Entretanto, verificou-se neste estudo que Azadirachta indica A. Juss (10,45\%), Senna siamea (11,94\%) e Ficus benjamina L. $(52,24 \%)$ ultrapassaram o percentual máximo por espécie, da mesma forma que a família Moraceae, da qual Ficus benjamina L. pertence.

Como também ocorreu nesse estudo, Brito et al. (2012), realizando um diagnóstico de praças públicas no município de Bom Jesus-PI, verificam duas espécies com percentual de indivíduos acima do recomendado, mesmo quantitativo observado por Santos et al. (2013) na análise da arborização de praças em Gurupi-TO.

Por outro lado, verificou-se que $50 \%$ das espécies encontradas possui apenas um indivíduo plantado, fato também observado por Martins et al. (2014) em estudo no município de Santa Rosa da Serra - MG, onde constataram que $60 \%$ das espécies apresentavam apenas um indivíduo. Segundo os autores, este fato pode ser um indicativo que a arborização ocorreu sem planejamento, podendo ter sido realizada aleatoriamente, pela população.

Considerando a origem das espécies utilizadas na arborização das praças, 91,7\% é de procedência exótica. Apenas uma espécie, que corresponde a 8,3\% é nativa do território brasileiro. Ao analisar a composição florística e a estrutura fitossociológica da vegetação de praças do município de Nossa Senhora do Socorro-SE, Jesus et al. (2015) constataram uma predominância de espécies exóticas (70,5\%). Santos (2019) na análise da arborização de praças em Teixeira de Freitas-BA, observaram um percentual de 76,48\%. Da mesma forma, Rezende et al. (2010) em Uberlândia-MG, Santos et al. (2011) em Crato-CE, Souza et al. (2019) em Cuiabá-MT e Falcão et al. (2020) em Jerônimo Monteiro-ES também verificaram predominância de espécies exóticas na avaliação da arborização de praças públicas urbanas, demonstrando que o uso de espécies exóticas é uma prática comum em muitos municípios brasileiros.

De acordo com Ziller et al. (2007) a utilização de espécies exóticas na arborização urbana pode causar diversos impactos ambientais, com consequências para a biodiversidade, a economia e/ou para a cultura dos centros urbanos, estendendo-se até a áreas de proteção ambiental. Lima et al. (2015) ressaltam a importância da flora nativa na arborização de praças urbanas, uma vez que desempenha importante papel no equilíbrio ambiental.

A praça da Matriz apresentou a maior número de indivíduos plantados (32), enquanto que a praça Teixeira de Freitas conta com 15 indivíduos e as praças José Tonico e Magalhaes de Almeida apresentaram o menor número (10).

\section{Análise Fitossociológica}

Na Tabela 3 estão apresentados os dados referentes à riqueza de espécies das áreas estudadas. Por meio deste parâmetro ecológico constatou-se que a Praça José Tonico, embora não possua a maior quantidade de indivíduos, apresentou a maior diversidade de espécies (7). As demais praças, por sua vez, mostraram-se menos diversificadas, com quatro espécies cada uma. Os valores encontrados nesta pesquisa foram superiores aos constatados por Moreira et al. (2018), os quais, ao estudarem nove praças no município 
de Planalto-BA, observaram somente uma com quatro espécies diferentes e as demais, com no máximo duas espécies.

Tabela 3: Índices de diversidade da arborização das quatro praças públicas do município de Dom Pedro-MA.

\begin{tabular}{lcccc}
\hline Praças & $\mathbf{S}$ & $\mathbf{H}^{\prime}$ & $\mathbf{J}^{\prime}$ & $\mathbf{D}^{\prime}$ \\
\hline José Tonico & 7 & 1,60 & 0,82 & 0,82 \\
Magalhães de Almeida & 4 & 1,09 & 0,78 & 0,58 \\
Matriz & 4 & 0,70 & 0,50 & 0,36 \\
Teixeira de Freitas & 4 & 1,14 & 0,82 & 0,62 \\
\hline
\end{tabular}

Nota: $\mathrm{S}$ = número de espécies; $\mathrm{H}^{\prime}$ = Índice de Shannon-Weaver; J' = equabilidade de Pielou; $\mathrm{D}^{\prime}$ = índice de Simpson.

Os índices de diversidade florística encontram-se apresentados na Tabela 3. Estes índices ecológicos representam a maneira mais usual de representação e quantificação da variação existente entre as espécies de uma comunidade biológica (SCOLFORO et al., 2008), sendo determinados pela combinação de dois atributos: o número de espécies e sua equabilidade (MELO, 2008).

A amplitude do índice de diversidade de Shannon-Weaver $\left(H^{\prime}\right)$ variou de 0,70 (praça da Matriz) a 1,60 (praça José Tonico). De acordo com Floriano (2009) áreas que apresentam valores inferiores a 1,5 possuem baixa diversidade e entre 1,5 e 3,5 são consideradas de média diversidade. Para o autor, existe alta diversidade quando os valores são superiores a 3,5 e raramente são encontrados valores superiores a 4,5. Portanto, constatou-se que a praça José Tonico apresentou média diversidade de espécies, enquanto que as demais, podem ser classificadas como de baixa diversidade. Provavelmente, este fato deve-se a um melhor planejamento da arborização, haja vista que é a mais jovem dentre as praças pesquisadas.

Utilizando os mesmos índices propostos pelos autores supracitados, Teixeira et al. (2016) e Bernardes et al. (2019), também classificou as praças públicas analisadas em São Gabriel-RS e Iporá-GO, respectivamente, como de média diversidade, fato semelhante ao evidenciado no presente estudo, com a praça José Tonico.

As praças Magalhães de Almeida, José Tonico e Teixeira de Freitas apresentaram elevados índices de equabilidade. A primeira apresentou um valor de 0,78 e as últimas de 0,82. Desta forma, os dados sugerem que essas praças possuem uma composição paisagística com alta uniformidade entre a quantidade de indivíduos e as espécies plantadas, pois de acordo com Melo (2008) a equabilidade diz respeito ao quão similar as espécies são representadas numa comunidade biológica. Valor de equabilidade similar foi observado por Lindenmaier et al. (2008) em praças de Cachoeira do Sul-RS, 0,79. A praça da Matriz apresentou o menor valor de equabilidade, 0,50 (Tabela 3).

Conforme visualizado na Tabela 3, a amplitude do índice de diversidade Simpson ( $D^{\prime}$ ) variou de 0,36 (praça da Matriz) a 0,82 (praça José Tonico). Importante ressaltar que a praça da Matriz possui o maior quantitativo de indivíduos (32), entretanto, apresenta o mesmo número de espécies que as praças Teixeira de Freitas e Magalhães de Almeida, que possuem 15 e 10 indivíduos, respectivamente. Essa condição, faz com que a praça apresente a menor diversidade $\left(H^{\prime}=0,70\right.$ e $\left.D^{\prime}=0,36\right)$, bem como menor similaridade entre as espécies $\left(J^{\prime}=0,50\right)$. Desta forma, verifica-se a necessidade de redução do número de indivíduos da espécie Ficus benjamina L., que ocupa cerca de $78 \%$ do percentual de indivíduos, substituindo-os por outras árvores de origem nativa da região. 
Em termos de similaridade da composição florística das praças, elaborou-se um dendrograma para analisar os agrupamentos formados, conforme visualiza-se na Figura 2. O nível de corte adotado foi de $25 \%$ (SCOLFORO et al., 2008).

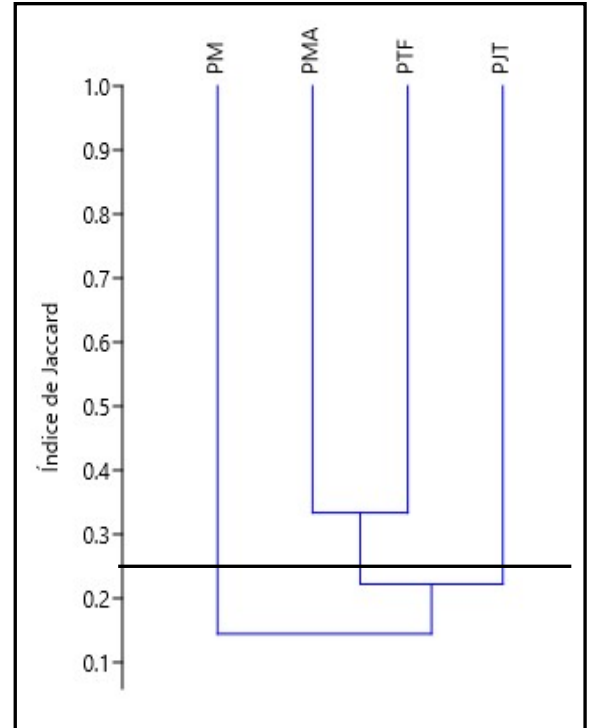

Figura 2: Similaridade da composição florística entre as quatro praças estudadas, definida pelo método de UPGMA, com base no Coeficiente de Jaccard. (PM = Praça da Matriz; PMA = Praça Magalhães de Almeida; PTF = Praça Teixeira de Freitas; PJT = Praça José Tonico).

Verifica-se na Figura 2 a existência de três grupos formados, a partir da linha de corte na posição 25\%. O primeiro, representado pela praça da Matriz, o segundo composto pelas praças Magalhães de Almeida e Teixeira de Freitas, que apresentaram maior grau de similaridade e o terceiro formado apenas pela praça José Tonico.

Neste estudo, o coeficiente de Jaccard variou de 0,14 a 0,33. De acordo com Sousa et al. (2009), valores maiores ou iguais a 0,50 indicam alta similaridade entre os agrupamentos e a máxima semelhança é alcançada no valor 1,0. Deste modo, as praças estudadas possuem baixa similaridade, o que implica dizer que existe uma alta variedade de espécie entre as praças, o que é positivo do ponto de vista ambiental, haja vista a maior biodiversidade na área urbana.

\section{CONCLUSÕES}

Nas quatro principais praças públicas do município de Dom Pedro-MA foram identificados 67 indivíduos, distribuídos em 12 espécies e 8 famílias botânicas. Arecaceae e Fabaceae apresentaram-se como as famílias de maior ocorrência, respondendo por $50 \%$ do total encontrado. Somente a espécie Ficus benjamina L. responde por $52,24 \%$ de todos os indivíduos plantados. Desta forma, deve-se evitar o plantio desta espécie em novas áreas verdes urbanas e, até mesmo, fazer a substituição de alguns de seus indivíduos por outros pertencentes a espécies nativas da região, já que apenas $8,3 \%$ das espécies presentes nas praças são nativas.

A maioria das praças (75\%) foi classificada como de baixa diversidade de espécies. Em termos de similaridade, as praças Magalhaes de Almeida e Teixeira de Freitas apresentaram maior semelhança em sua composição florística. 


\section{REFERÊNCIAS}

AMORIM, L. D. M.; SOUSA, L. O. F.; OLIVEIRA, F. F. M.; CAMACHO, R. G. V.; MELO, J. I. M.. Fabaceae na Floresta Nacional (FLONA) de Assú, semiárido potiguar, nordeste do Brasil. Rodriguésia, Rio de Janeiro, v.67, n.1, p.105-124, 2016. DOI: https://doi.org/10.1590/2175-7860201667108

APG III. An update of the Angiosperm Phylogeny Group classification for the orders and families of flowering plants: APG III. Botanical Journal of the Linnean Society, v.161, n.2, p.105-121, 2009.

BAUMANN, S. S. R. T.; BRÍGIDA, C. A. S.; SILVA, J. B. S.; LIMA, P. S.; RABELA, L. K. L.; PIRES, E. C.; MAESTRI, M. P.; AQUINO, M. G. C.. Espécies arbóreas tóxicas presentes na arborização urbana do município de Santarém, Pará. Revista IberoAmericana de Ciências Ambientais, v.10, n.3, p.342-351, 2019. DOI: https://doi.org/10.6008/CBPC2179$\underline{6858.2019 .003 .0029}$

BERNARDES, A. M. A.; MOURA, T. M.; DINIZ, V. S. S.; DIAS, M. A.; MARQUES, M.. Levantamento florístico e fitossociológico do componente arbóreo de praças públicas do município de Iporá, Goiás. Revista Verde de Agroecologia e Desenvolvimento Sustentável, v.14, n.3, p.436-442, 2019. DOI: http://doi.org10.18378/rvads.v14i3.6596

BRITO, D. R. S.; RAABE, J.; SOUSA, W. C.; MELO, R. R.; PEDROSA, T. D.. Diagnóstico da arborização das praças pública no município de Bom Jesus, Piauí. Scientia plena, v.8, n.4(b), 2012.

CEMIG. Companhia Energética de Minas Gerais. Manual de arborização. Belo Horizonte: CEMIG, 2011.

CORREIA FILHO, F. L.; GOMES, É. R.; NUNES, O. O.; LOPES FILHO, J. B.. Projeto cadastro de fontes de abastecimento por água subterrânea: estado do Maranhão: relatório diagnóstico do município de Dom Pedro. CPRM, 2011.

DANTAS, A. R.; GOMES, E. M. C.; PINHEIRO, A. P.. Diagnóstico florístico da praça Floriano Peixoto na cidade de Macapá, Amapá. Revista da Sociedade Brasileira de Arborização Urbana, v.11, n.4, p.32-46, 2016. DOI: http://dx.doi.org/10.5380/revsbau.v11i4.63494

FALCÃO, R. S.; GOMES, R.; PERES, M. Z.; OLIVEIRA, J. T.; CALLEGARO, R. M.. Análise quali-quantitativa da arborização de cinco praças em Jerônimo Monteiro, Espírito Santo. Revista da Sociedade Brasileira de Arborização Urbana, v.15, n.2, p.90-103, 2020. DOI:

http://dx.doi.org/10.5380/revsbau.v15i2.72563

FLORIANO, E. P.. Fitossociologia florestal. São Gabriel: UNIPAMPA, 2009.

FREITAS, W. K.; PINHEIRO, M. A. S.; ABRAHÃO, L. L. F.. Análise da Arborização de Quatro Praças no Bairro da Tijuca, RJ, Brasil. Floresta e Ambiente, v.22, n.1, p.23-31, 2015. DOI: http://dx.doi.org/10.1590/2179-8087.025612

GATTI, S.. Espaços Públicos: diagnóstico e metodologia de projeto. Coordenação do Programa Soluções para Cidades. São Paulo: ABCP, 2013.
HAMMER, $\varnothing$.; HARPER, D.A.T; RYAN, P. D.. PAST: Paleontological Statistics Software package for Education and Data Analysis. Palaeontologia Electronica, California, v.4, p.1-9, 2001.

IBGE. Instituto Brasileiro de Geografia e Estatística. Cidades. Dom Pedro: IBGE, 2019.

JESUS, J. B.; VALENÇA JUNIOR, R. R.; Mello, A. A.; Ferreira, R. A.. Análise da arborização de praças do município de Nossa Senhora do Socorro/SE. Revista da Sociedade Brasileira de Arborização Urbana, v.10, n.2, 2015. DOI: http://dx.doi.org/10.5380/revsbau.v10i2.63084

LIMA, J. P.; KREUTZ, C.; PEREIRA, O. R.. Levantamento florístico das espécies utilizadas na arborização de praças no município de Nova Xavantina/MT. Revista da Sociedade Brasileira de Arborização Urbana, v.10, n.3, p.60-72, 2015. DOI: http://dx.doi.org/10.5380/revsbau.v10i3.63216

LINDENMAIER, D. S.; SANTOS, N. O.. Arborização urbana das praças de Cachoeira do Sul, RS, Brasil: fitogeografia, diversidade e índice de áreas verdes. Pesquisas, Botânica, São Leopoldo, v.1, n.59, p.307-320, 2008.

MARTINS, L. C.; NUNES, A. L.; NUNES, A. M.; BRAGA, H. S.. Análise comparativa da arborização urbana de três cidades da região do Alto São Francisco/Minas Gerais. Revista Agrogeoambiental, v.6, n.2, 2014.

MELO, A. S.. O que ganhamos' confundindo'riqueza de espécies e equabilidade em um índice de diversidade?. Biota Neotropica, v.8, n.3, p.21-27, 2008.

MORAES, L. A.; MACHADO, R. R. B.; ARAÚJO, M. F. V.. O babaçu na zona urbana de Teresina/PI: distribuição e viabilidade paisagística. Revista Equador, v.4, n.4, p.112-132, 2015.

MOREIRA, G. L.; LIMA, M. C. D.; ROCHA, M.B.; CUNHA, D. V. P.; FERRAZ, F. T.. Diagnóstico quali-quantitativo da arborização de praças públicas do município de Planalto, Ba. Agropecuária Científica No Semiárido, v.14, n.2, p.168-174, 2018. DOI: http://dx.doi.org/10.30969/acsa.v14i2.1019

REZENDE, T. M.; SANTOS, D. G.. Avaliação quali-quantitativa da arborização das praças do bairro Jaraguá, Uberlândia/MG. Revista da Sociedade Brasileira de Arborização Urbana, v.5, n.2, p.139-157, 2010.

SANTAMOUR JÚNIOR, F. S.. Trees for urban planting: diversity uniformity, and common sense. Washington: U.S. National Arboretum, Agriculture Research Service, U.S. Department of Agriculture Washington, 2002.

SANTOS, A. F.; JOSÉ, A. C.; SOUSA, P. A.. Fitossociologia e diversidade de espécies arbóreas das praças centrais do município de Gurupi-TO. Revista da Sociedade Brasileira de Arborização Urbana, v.8, n.4, p.36-46, 2013. DOI: http://dx.doi.org/10.5380/revsbau.v8i4.66511

SANTOS, A. C. B.; SILVA, M. A. P.; SOUZA, R. K. D.. Levantamento florístico das espécies utilizadas na arborização de praças no município de Crato, CE. Caderno 
de Cultura e Ciência, v.10, n.1, p.13-18, 2011.

SANTOS, J. F.. Análise quali-quantitativa e nível de adequação da arborização em três praças públicas no município de Teixeira de Freitas, BA. Revista Mosaicum, n.29, p.107-122, 2019.

SCOLFORO, J. R.; OLIVEIRA, A. D.; FERRAZ FILHO, A. C.; MELLO, J. M.. Diversidade, equabilidade e similaridade no domínio da caatinga. Inventário Florestal de Minas Gerais: Floresta Estacional Decidual-Florística, Estrutura, Similaridade, Distribuição Diamétrica e de Altura, Volumetria, Tendências de Crescimento e Manejo Florestal. Lavras: UFLA, 2008.

SILVA, C. D, D.; ALMEIDA, L. M.. Composição florística e fitossociológica das praças do bairro de Neópolis, Natal-RN. Carpe Diem: Revista Cultural e Científica do UNIFACEX, v.14, n.2, p.86-103, 2016.

SILVA, L. S.; OLIVEIRA, Y. R.; SILVA, P. H.; PIMENTEL, R. M. M.; ABREU, M. C.. Inventário das plantas arbustivo-arbóreas utilizadas na arborização urbana em praças públicas. Journal of Environmental Analysis and Progress, v.3, n.2, p.241-249, 2018. DOI:

https://doi.org/10.24221/jeap.3.2.2018.1834.241-249

SILVA, M. B.; FERREIRA, J. T. P.; PETRAUSKAS, F. J. S. B.;
TEOTONIO, F. B.; SILVA, M. O.; PRATES, F. B. S.; FERREIRA, E. P.. Inventário e diagnóstico da arborização urbana do município de piranhas-AL. Revista Craibeiras de Agroecologia, v.1, n.1, 2017.

SOARES, J.; PELLIZZARO, L.. Inventário da Arborização Urbana do município de Ampére (Paraná-Brasil). Revista Brasileira de Meio Ambiente, v.5, 2019.

SOUZA, R. M.; DUARTE, T. G.; PASA, M. C.. Plantas lenhosas e palmeiras das praças da cidade de Cuiabá, MT.

Biodiversidade, v.18, n.3, 2019.

TEIXEIRA, I. F.; FIGUEIREDO, F. M.; TABORDA, I. R.; SOARES, L. M.. Análise fitossociológica da praça Camilo Mércio no centro histórico de São Gabriel, RS. Revista SBAU,

Piracicaba, v.11, n.1, p.01-13, 2016. DOI: http://dx.doi.org/10.5380/revsbau.v11i1.63236

VIEIRA, T. A.; PANAGOPOULOS, T.. Urban Forestry in Brazilian Amazônia. Sustainability, 2020. DOI: https://doi.org/10.3390/su12083235

ZILLER, S. R.; ZENNI, R. D.; DECHOUM, M. S.. Espécies exóticas invasoras na arborização urbana: problemas e soluções. In: CONGRESSO BRASILEIRO DE ARBORIZAÇÃO URBANA. Anais. Vitória: SBAU, 2007. 